\title{
非华裔生汉语学习焦虑调查 -一以玛拉工艺大学为例
}

Hie Ling TING ${ }^{1 *}$

Academy of Language Studies, Universiti Teknologi MARA (UiTM) Sarawak, 96400 Mukah, Sarawak, Malaysia

\section{Jiin Yih YEO ${ }^{2}$}

Academy of Language Studies, Universiti Teknologi MARA (UiTM) Sarawak, 94300 Kota Samarahan, Malaysia

\author{
Vicky CHIN ${ }^{3}$ \\ SMK Spaoh, Betong \\ ${ }^{1} 1$ tinghieling@gmail.com* \\ 2 yeoji242@sarawak.uitm.edu.my \\ 3 cwszev@gmail.com
}

*Corresponding author

Manuscript received 17 June 2016

Manuscript accepted 7 November 2016

\begin{abstract}
摘要
汉语作为外语或第三语言学习对非华裔生来说无疑是一项挑战。在汉语学习过 程中, 非华裔生必定承受一定程度的外语学习焦虑。有鉴于此, 本文以砂拉越 玛拉工艺大学选修汉语作为外语学习的221名非华裔生作为研究对象, 对非华 裔生的焦虑程度和焦虑因素进行调查。本文采用以赫维兹等人（Horwitz, Horwitz \& Cope）（1986）设计的外语学习焦虑量表, 简称FLCAS （Foreign Language Classroom Anxiety Scale）作为调查工具。在问卷收集 完善后, 笔者采用SPSS 22.0作为数据统计工具。调查结果显示, 大部分 非华裔生的汉语学习焦虑水平处于中度焦虑, 而导致非华裔生汉语学习焦虑的 因素从高至低依次是交际焦虑（Communication Apprehension），负评价焦虑 （Fear of Negative Evaluation） 及测试焦虑（Test anxiety）。
\end{abstract}

关键词: 汉语, 学习焦虑, 非华裔生, 因素 


\title{
MANDARIN LANGUAGE LEARNING ANXIETY AMONG NON-CHINESE LEARNERS: A CASE OF UNIVERSITI TEKNOLOGI MARA
}

\begin{abstract}
Learning Mandarin as a foreign language or third language can be very difficult for non-Chinese learners. In the process of learning Mandarin, non-Chinese learners may experience certain level of foreign language anxiety. The objectives of this study are to investigate Mandarin language anxiety level and its associated factors among non-Chinese learners. This study involved 221 non-Chinese learners who enrolled in Introductory Mandarin Language in Universiti Teknologi MARA (UiTM), Sarawak. The instrument for this study included the Foreign Language Classroom Anxiety Scale (FLCAS) developed by Horwitz, Horwitz and Cope (1986). The collected data were analysed using Statistical package for Social Science (SPSS) 22. The results of the study indicated that most of the non-Chinese learners experienced a moderate level of anxiety while learning Mandarin. The main factor that contributed to their language anxiety was communication apprehension, followed by fear of negative evaluation and test anxiety.
\end{abstract}

Keywords: Chinese language, learning anxiety, non-Chinese learner, factor

\section{前言}

20世纪40年代, 语言焦虑这一概念最先在第二语言习得研究领域提出（何珊, 2014）。自20世纪70年代, 外语研究者逐渐将外语研究重心转向学习者在语言 学习过程中的焦虑。在众多研究者中, 以赫维兹等人（Horwitz, Horwitz \& Cope）的研究最具代表性。他们对外语学习焦虑进行了大量深入的研究（张莉 , 2006）。赫维兹等人认为, “外语焦虑是一种产生于外语学习过程, 和课堂外 语学习相联系的有关自我知觉、信念、情感和行为的独特的综合体”, 包括交际 焦虑 (communication apprehension)、测试焦虑（test anxiety）和负评价焦虑 （fear of negative evaluation）三个要素（赵维伦\&刘丰，2011）。交际焦虑主 要指个人对与他人的真实或者预期焦虑产生的恐惧或焦虑程度, 其行为模式是 交际回避（avoidance）或者退缩（withdrawal），与没有交际焦虑的人相比， 有交际焦虑的人不愿意参与他人的会话以及社交。测试焦虑指学习者受个人的 认知、个性、特点等的影响, 产生对考试成败的担忧和情绪紧张为主要特征的 心理反应状态，进而对他们考试成绩产生负面影响。负评价焦虑是指学习者过 分担心自己的成绩和个人表现，不愿意给人留下不好的印象。具有负评价焦虑 的人在人际交际及完成任务的过程中会产生“己不如人”的感觉，而这种经常性 的心理暗示会挫伤学生的自尊心和自信心, 使其在开展任务或考试前就产生比 较明显的焦虑情绪（周凤敏, 2013）。

为了研究外语学习焦虑这一心理活动, 赫维兹等人 (Horwitz

al.）根据学生的自我报告、客观实验以及一系列相关测量方法的分析整理, 设 计出一个后来被广泛采用的外语学习测量方法一一外语课堂焦虑量表（Foreign

Language Classroom Anxiety Scale），用于测量外语学习焦虑的广度和深度 （唐美玲, 2006）。使用这一量表进行多次实验后, Horwitz得出如下结论：迄 
今为止的实验结果证明, 外语学习焦虑是可以有效且可信地进行测量的（王银 泉\&万玉书, 2001)。通过研究发现外语课堂焦虑在外语学习者中普遍存在（ 周凤敏，2013）。

纵然许多研究证明学习者在学习语言时确实面临语言学习焦虑, 但研究 中仍然存在一些局限。较多的研究皆以英语作为第二语言的学习焦虑为主, 对 于汉语作为外语的学习焦虑研究, 尤其是针对非华裔生的汉语学习焦虑研究并 不多。有鉴于此, 本文将以问卷调查的方式来了解非华裔生的汉语学习焦虑程 度和因素。本文研究问题如下:（1）玛拉工艺大学非华裔生的汉语学习焦虑 处于什么水平, (2) 什么因素导致非华裔生的汉语学习焦虑。针对问题的提 出, 本文的研究目的有, (1) 探讨玛拉工艺大学非华裔生的汉语学习焦虑水 平, (2) 了解并确认玛拉工艺大学非华裔生的汉语学习焦虑因素。

\section{文献探索}

焦虑是指“个体由于不能达到预期的目标或者不能克服障碍的威胁，使得其自尊 心与自信心受挫, 或使失败感和内疚感增加而形成的紧张不安, 带有恐惧感的 情绪状态, 它是外语学习中最主要的情感障碍”（史利红, 2014）。对外汉语研 究者也注意到焦虑这一情感因素对汉语作为外语学习的影响, 因而对其学习焦 虑进行了实证研究, 并取得了一定的成果。

李小花 (2012) 研究了藏族学生外语课堂焦虑。文中中采用了《外语课 堂焦虑量表》对青海警官职业学院的87名藏族学生的外语课堂焦虑状况进行了 调查。调查结果发现, 藏族学生在外语学习中经历中度焦虑, 而影响他们课堂 焦虑依次排列是交际焦虑、负评价恐惧和考试焦虑。李氏在同文中也通过数据 分析探讨青海警官职业学院藏族学生英语学习焦虑与英语成绩之间的关系。分 析结果显示外语课堂焦虑与英语成绩呈负相关关系。这就说明学生在课堂中焦 虑感越强英语成绩就越低。此外, 李氏也在同文中对性别在外语课堂焦虑与英 语学习中的影响进行了差异性分析。分析结果显示, 性别在外语课堂焦虑上存 在着显著的差异, 也就说明不同的性别影响外语课堂焦虑。

徐劦思与李敬梅（2015）以某高校的121名对口中职单独录取的学生简称 单招生作为研究对象, 采用Foreign Language Classroom Anxiety Scale (FLCAS) 对该高校单招生英语作为外语学习焦虑进行了调查。通过调查结果发现, 高校 单招生存在着较强的外语学习焦虑, 而导致单招生外语学习焦虑的主要因素是 害怕外语学习失败。在交际焦虑、考试焦虑、害怕负面的评价、英语课的消极 态度和害怕英语学习的失败这五种焦虑中, 学生的考试焦虑程度是最低的。在 同文中, 徐氏和李氏也针对调查分析结果提出一些建议, 如: 为学生创造真实 的语言环境, 以减轻学生的交际焦虑、尽量设计多种多样的课堂活动、注意纠 错方式以及多与学生交流以了解他们学习上的困难。

郝秋兰 (2014) 在研究土库曼斯坦预科留学生汉语学习焦虑时, 结合了 问卷调查、课堂观摩和个人访谈的调查方式对华中师范大学国际文化交流学院 的土库曼预科留学生的汉语学习焦虑进行了研究。结果表明导致土库曼预科留 学生的汉语学习存在着焦虑, 焦虑感呈中等水平焦虑。郝氏通过T检验的分析 结果显示, 不同班级环境学生的焦虑值有差异, 表明环境在语言习得过程有着 重要的作用。另外, 不同英语水平与汉语学习焦虑没有明显的差异。通过焦虑 
原因量表和个人访谈结果则显示，在学习汉语时产生的焦虑的原因有八个，当 中包括学习环境、汉语自身的特点、自我评价、教材翻译、教师的纠错方式、 学生英语水平、文化差异和学习习惯。郝氏在文末建议教师向学生传授应对焦 虑的方法、创造轻松愉悦的学习环境、培养学生良好的学习习惯和合理选择和 使用教材。

彭虹（2012）对泰国初中生汉语学习焦虑状况以及成因进行了研究。研 究以泰国红统府萨迪安通学校120名泰国初中一学生为例, 调查了泰国初中生 的汉语学习焦虑的总体情况、各焦虑组的焦虑情况、与焦虑程度相关的个体因 素、语言基本技能焦虑和焦虑产生原因。研究结果发现, 初中生的汉语学习焦 虑普遍存在。高焦虑组学生在回答老师的问题时表现被动; 在迫于无奈的情况 下说话时焦虑感最高。根据文中对泰国初中生汉语学习焦虑原因的研究结果显 示, 汉语本身和学生自身因素的焦虑原因是令学生产生焦虑感的原因。另外在 同文中也提到最不会令学生产生焦虑的原因是“文化背景”, “教材内容”以及“教 师教学方法”。

李宁（2013）采用《外语学习焦虑量表》对广西高校的东南亚留学生进 行了问卷调查、访谈及课堂观察等, 以调查学习者的汉语学习焦虑情况和个体 差异状况。其研究结果显示, 广西部分高校东南亚留学生的汉语学习焦虑属中 度焦虑。另外, 其研究成果也发现, 学习者的个体差异 (如: 学习经历、汉语 水平的主观评价) 影响留学生的汉语学习焦虑。在取得研究成果后, 李氏在文 中也提出了一些相应的教学、学习以及管理建议。李氏对教师提出的建议有: 培养学习者的学习兴趣、培养跨文化交际能力、营造轻松愉快的课堂氛围等。 在东南亚留学生学习方面, 李氏则建议东南亚留学生应该合理应对考试焦虑、 增强自信、积极使用汉语进行交际、客观地评价自身的语言学习、并正视语言 学习的挫折。对学校相关管理机构的建议则是完善课程设置、完善留学生的分 班制度和探索及改革留学生的住宿模式。

根据上述的文献综述来看, 各项研究选取的研究对象都是外语学习者, 有者把英语作为外语学习, 有些则把汉语作为外语学习。由于英语作学习焦虑 在西方研究者的基础上获得了全面的探讨, 因此笔者也在此对英语作为外语学 习焦虑的研究做了简洁的综述, 以作为本文调查的参考。在文献探讨过程中笔 者发现, 虽然外语学习焦虑研究取得了丰硕的成果, 但较多的外语皆以英语为 主。对于汉语作为外语学习焦虑研究大多集中在欧美、日韩国家留学生（郝秋 兰, 2014）, 而针对非华裔生的汉语学习焦虑的研究有限。因此, 笔者将在本 文中针对玛拉工艺大学非华裔生的汉语学习焦虑进行调查。

\section{研究方法}

\section{调查对象}

本文被试者为随机选取的砂拉越玛拉工艺大学选修汉语作为外语学习的非华裔 生。本次调查发放问卷 221 份, 其中男生人数为 39 人, 占总数 $17.6 \%$, 女生人数 为 182 人，占总数 $82.4 \%$ 。被试者年龄介于 $19-$

26岁之间。他们分别是工商管理系, 会计系, 科学系和行政管理系的学生。 


\begin{tabular}{|c|c|c|c|c|c|c|c|c|c|}
\hline & \multicolumn{2}{|c|}{ 性别 } & \multicolumn{4}{|c|}{ 专业 } & \multicolumn{3}{|c|}{ 汉语学习阶段 } \\
\hline & 男 & 女 & 工商管理系 & 会计系 & 科学系 & 行政管理系 & 1 & 2 & 3 \\
\hline 人数 & 39 & 182 & 76 & 65 & 11 & 69 & 101 & 66 & 54 \\
\hline 百分比 & 17.6 & 82.4 & 34.4 & 29.4 & 5 & 31.2 & 45.7 & 29.9 & 24.4 \\
\hline
\end{tabular}

\section{调查工具及数据处理}

本文调查采用了赫维兹等人（Horwitz et al., 1986）所设计的 《外语学习焦 虑量表》, 简称FLCAS (Foreign Language Classroom Anxiety Scale)。 FLCAS量表主要研究外语学习者的课堂学习焦虑。FLCAS量表 被研究者广泛 地用以研究外语学习（Aida, 1994; Matsuda \& Gobel, 2001）。因此, FLCAS量表 在研究外语学习焦虑的可信度是无可否认的。

由于本文将对非华裔生的汉语学习焦虑进行调查，因此笔者将量表中的 “外语”一词改为“汉语”。FLCAS量表共有33个项目（见表三、四和五），依据赫 维兹等人的研究共分为三个维度, 即交际焦虑、测试焦虑和负评价焦虑。33个 项目中有 9 个 反向问题, 在统计数据时反向计算数据。问卷于学期末在课堂 发放给学生作答。问卷调查完成后, 用SPSS 22.0统计软件进行数据分析。

\section{结果分析与讨论}

本节将对问卷分析结果进行讨论。笔者将全部33个项目的分数相加以找出玛拉 工艺大学非华裔生的汉语学习焦虑水平总情况,

得分越高表示焦虑水平越高。为了确认非华裔生的汉语学习焦虑水平, 本文按 照李克特（Likert）五点计分法，从“完全不同意”（1分）到“完全同意”

（5分），因此，其焦虑值在33-165之间。若将焦虑水平划分为高、中、低， 那么其焦虑值分类是：低度焦虑（33-89），中度焦虑（90-108）和高度焦虑 （109-165）。据结果分析, 49.8\%的非华裔生, 即 110 人在学习汉语时表现 的焦虑水平处于中度焦虑, $41.6 \%$ 的非华裔生, 即 92 人的汉语学习焦虑水平 处于高度焦虑。仅有 $8.6 \%$, 即占总人数 19 人的非华裔生在学习汉语时表现低度 焦虑。调查结果证明, 非华裔生的汉语学习焦虑普遍存在。这一结果与部分研 究汉语学习焦虑的研究结果一致（钱旭菁, 1999; 李宁, 2013)。

据表二所示，非华裔生汉语学习焦虑原因有三，从高至低依次是交际焦 虑 (Communication Apprehension), 负评价焦虑 (Fear of Negative Evaluation）, 测试焦虑（Test anxiety）。分析结果表明, 非华裔生汉语 学习焦虑的三大主因之交际焦虑是导致非华裔生汉语学习焦虑的主要因素, 其 平均焦虑值达3.29。非华裔生的负评价焦虑的焦虑值也普遍较高 (平均焦虑值= 3.26）。测试焦虑平均焦虑值为3.15是三大焦虑因素中平均焦虑值相对较低的 。为了更清楚非华裔生的汉语学习焦虑因素, 笔者将在接下来的部分, 根据汉 语学习焦虑三大因素的因子进行讨论。 
表二

非华裔生的汉语学习焦虑遍布情况

\begin{tabular}{cccc}
\hline & 均值 & 标准差 & 排序 \\
\hline 交际焦虑 & 3.29 & 0.440 & 1 \\
\hline 负评价焦虑 & 3.26 & 0.520 & 2 \\
\hline 测试焦虑 & 3.15 & 0.399 & 3 \\
\hline
\end{tabular}

\section{交际焦虑}

首先，笔者就交际焦虑因子的均值分布进行讨论。非华裔生的交际焦虑主要表 现在“上汉语课时，当我没有准备就要开始说汉语时，我会感到惊慌失措”，均 值为3.73。另外, “当我在汉语课上听不懂汉语老师在说些什么时, 我会感到害 怕”和“当我听不懂汉语老师所说的每一个字时, 我会紧张”这两个因子的均值高 达3.41。在外语学习过程中, 学习者常常会碰到语言模糊的现象。这些模糊现 象会引起焦虑, 使得语言学习者无法继续学习（李洪波\&刘莉, 2008）。非华 裔生会因为语言模糊现象而焦虑时，会使非华裔生在“上汉语课说汉语时，会感 到紧张和困惑”（均值=3.26）, 更会在“不了解老师所订正的汉语时, 感到烦恼 ”（均值=3.19），进而在“上汉语课时，对说汉语没把握”（均值=3.12）。此外 , 由于汉语语法与非华裔生的本族语言语法有异, 因此“在学说汉语时, 被汉语 语法压得喘不过气”（均值=3.18）一说, 也是非华裔生在学说汉语时产生交际 焦虑的因素。

表三

交际焦虑因子之百分比, 均值和标准差分析结果

\begin{tabular}{|c|c|c|c|c|c|c|c|}
\hline 交际焦虑因子描述 & 1 & 2 & 3 & 4 & 5 & $\begin{array}{l}\text { 均 } \\
\text { 值 }\end{array}$ & $\begin{array}{l}\text { 标 } \\
\text { 准 } \\
\text { 差 }\end{array}$ \\
\hline 上汉语课时, 我对说汉语没把握 & $\begin{array}{l}2.7 \\
(6)\end{array}$ & $\begin{array}{l}14.9 \\
(33)\end{array}$ & $\begin{array}{l}54.3 \\
(120)\end{array}$ & $\begin{array}{l}23.5 \\
(52)\end{array}$ & $\begin{array}{l}4.5 \\
(10)\end{array}$ & 3.12 & 0.813 \\
\hline $\begin{array}{l}\text { 当我在汉语课上听不懂汉语老师 } \\
\text { 在说些什么时, 我会到害怕。 }\end{array}$ & $\begin{array}{l}0.9 \\
(2)\end{array}$ & $\begin{array}{l}19.9 \\
(44)\end{array}$ & $\begin{array}{l}25.8 \\
(57)\end{array}$ & $\begin{array}{l}43.4 \\
(96)\end{array}$ & $\begin{array}{l}10 \\
(22)\end{array}$ & 3.41 & 0.947 \\
\hline $\begin{array}{l}\text { 上汉语课时, 当我没有准备就要 } \\
\text { 开始说汉语时, 我会感到惊慌失 } \\
\text { 措。 }\end{array}$ & $\begin{array}{l}2.3 \\
(5)\end{array}$ & $\begin{array}{l}7.7 \\
(17)\end{array}$ & $\begin{array}{l}25.8 \\
(57)\end{array}$ & $\begin{array}{l}43 \\
(95)\end{array}$ & $\begin{array}{l}21.3 \\
(47)\end{array}$ & 3.73 & 0.956 \\
\hline $\begin{array}{l}\text { 我和华人说汉语时, 不会感到紧 } \\
\text { 张。 }\end{array}$ & $\begin{array}{l}13.6 \\
(30)\end{array}$ & $\begin{array}{l}36.7 \\
(81)\end{array}$ & $\begin{array}{l}32.1 \\
(71)\end{array}$ & $\begin{array}{l}14.9 \\
(33)\end{array}$ & $\begin{array}{l}2.7 \\
(6)\end{array}$ & 2.56 & 0.991 \\
\hline $\begin{array}{l}\text { 在上汉语课时, 我对说汉语有自 } \\
\text { 信。 }\end{array}$ & $\begin{array}{l}6.8 \\
(15)\end{array}$ & $\begin{array}{l}29.4 \\
(65)\end{array}$ & $\begin{array}{l}47.1 \\
(104)\end{array}$ & $\begin{array}{l}14.9 \\
(33)\end{array}$ & $\begin{array}{l}1.8 \\
(4)\end{array}$ & 2.75 & 0.854 \\
\hline $\begin{array}{l}\text { 在同学面前说汉语, 我觉得非常 } \\
\text { 不自在。 }\end{array}$ & $\begin{array}{l}2.7 \\
(6)\end{array}$ & $\begin{array}{l}13.1 \\
(29)\end{array}$ & $\begin{array}{l}58.4 \\
(129)\end{array}$ & $\begin{array}{l}24 \\
(53)\end{array}$ & $\begin{array}{l}1.8 \\
(4)\end{array}$ & 3.09 & 0.739 \\
\hline $\begin{array}{l}\text { 当我上汉语课说汉语时, 我会感 } \\
\text { 到紧张和困惑。 }\end{array}$ & $\begin{array}{l}0.9 \\
(2)\end{array}$ & $\begin{array}{l}17.2 \\
(38)\end{array}$ & $\begin{array}{l}41.6 \\
(92)\end{array}$ & $\begin{array}{l}34.8 \\
(77)\end{array}$ & $\begin{array}{l}5.4 \\
(12)\end{array}$ & 3.26 & 0.84 \\
\hline 当我听不懂汉语老师所说的每一 & 1.4 & 18.1 & 29.9 & 38.9 & 11.8 & 3.41 & 0.962 \\
\hline
\end{tabular}




\begin{tabular}{lccccccc}
\hline 个字时, 我会紧张。 & $(3)$ & $(40)$ & $(66)$ & $(86)$ & $(26)$ & & \\
\hline 在说汉语的人旁边, 我觉得轻松 & 5.4 & 20.8 & 53.8 & 17.2 & 2.7 & \multirow{2}{*}{2.90} & \multirow{2}{*}{0.837} \\
自在。 & $(12)$ & $(46)$ & $(119)$ & $(38)$ & $(6)$ & & \\
\hline 当我不了解老师所订正的汉语时 & 3.6 & 19.5 & 39.4 & 29 & 8.6 & \multirow{2}{*}{3.19} & \multirow{2}{*}{0.969} \\
, 我会感到烦恼。 & $(8)$ & $(43)$ & $(87)$ & $(64)$ & $(19)$ & & \\
\hline 学说汉语必须学很多文法, 压得 & 0.9 & 8.6 & 64.7 & 22.6 & 3.2 & \multirow{2}{*}{3.18} & \multirow{2}{*}{0.665} \\
我喘不过气。 & $(2)$ & $(19)$ & $(143)$ & $(50)$ & $(7)$ & & \\
\hline
\end{tabular}

1=非常不同意，2=不同意，3=一般，4=同意，5=非常同意

\section{负评价焦虑}

非华裔生汉语学习焦虑的诱因除了交际焦虑外, 还有负评价焦虑。负评价既包 括来自外部（教师、同学和考试结果等）的评估和改正所引起的伤害评价, 以 及自己对以往经历的消极归因 (如交际无能评价) 和对预期结果的威胁评价 ( 如考试会再次失败）（杨文漟\&章明明，2003）。

从表四可发现“认为其他同学的汉语比我好”或“总觉得其他学生的汉语 说得比我好”两个因子的均值相当高, 其均值分别是3.83和3.76。学生天性喜欢 把自己和同学比较, 一旦发现同学能力比自己强, 表现比自己好时, 就会产生 自己不如他人的心理, 久而久之便产生焦虑（李贤伟\&王金金, 2003)。另外, 周海燕（2007）也在其研究中提到, 在外语学习中, 学生习惯性在课堂学习中 与其他学习者竞争, 因此而产生超越其他学习者的欲望。然而, 当学习者发现 自己的竞争能力不及其他学习者时, 便会产生厌恶的情绪, 并产生焦虑。焦虑 的产生往往影响学习者的情绪, 让非华裔生在上汉语课时, “担心犯错”（均值= 3.04）。此外, 因为自尊心作崇, “害怕说汉语时, 其他同学会嘲笑”（均值=3.1 6)。为了维护自尊, 学生时刻处于高度焦虑状态, 害怕自己说错, 写错, 或 读错（李贤伟\&王金鍂, 2003）, 也因此非华裔生在“汉语老师问到一些没有事先 准备好的问题时，会感到紧张"（均值=3.76）。

表四

负评价焦虑因子之百分比, 均值和标准差分析结果

\begin{tabular}{|c|c|c|c|c|c|c|c|}
\hline 负评价焦虑因子描述 & 1 & 2 & 3 & 4 & 5 & $\begin{array}{l}\text { 均 } \\
\text { 值 }\end{array}$ & $\begin{array}{l}\text { 标 } \\
\text { 准 } \\
\text { 差 }\end{array}$ \\
\hline 上汉语课时, 我不担心犯错。 & $\begin{array}{l}6.8 \\
(15)\end{array}$ & $\begin{array}{l}26.2 \\
(58)\end{array}$ & $\begin{array}{l}27.6 \\
(61)\end{array}$ & $\begin{array}{l}33.9 \\
(75)\end{array}$ & $\begin{array}{l}5.4 \\
(12)\end{array}$ & 3.04 & 1.045 \\
\hline 我认为其他同学的汉语比我好。 & $\begin{array}{l}0 \\
0\end{array}$ & $\begin{array}{l}5.0 \\
(11)\end{array}$ & $\begin{array}{l}25.3 \\
(56)\end{array}$ & $\begin{array}{l}51.1 \\
(113)\end{array}$ & $\begin{array}{l}18.6 \\
(41)\end{array}$ & 3.83 & 0.782 \\
\hline $\begin{array}{l}\text { 要我上汉语课时, 自愿回答问题 } \\
\text { 时, 我会觉得困蹇不安。 }\end{array}$ & $\begin{array}{l}5.4 \\
(12)\end{array}$ & $\begin{array}{l}29 \\
(64)\end{array}$ & $\begin{array}{l}49.3 \\
(109)\end{array}$ & $\begin{array}{l}14.5 \\
(32)\end{array}$ & $1.8(4)$ & 2.78 & 0.824 \\
\hline $\begin{array}{l}\text { 我很害怕汉语老师纠正我的每一 } \\
\text { 个错误。 }\end{array}$ & $\begin{array}{l}9.5 \\
(21)\end{array}$ & $\begin{array}{l}36.7 \\
(81)\end{array}$ & $\begin{array}{l}43 \\
(95)\end{array}$ & $\begin{array}{l}9.5 \\
(21)\end{array}$ & $1.4(3)$ & 2.56 & 0.842 \\
\hline $\begin{array}{l}\text { 我总觉得其他学生的汉语说得比 } \\
\text { 我好。 }\end{array}$ & $\begin{array}{l}0 \\
0\end{array}$ & $\begin{array}{l}5.0 \\
(11)\end{array}$ & $\begin{array}{l}31.7 \\
(70)\end{array}$ & $\begin{array}{l}44.8 \\
(99)\end{array}$ & $\begin{array}{l}18.6 \\
(41)\end{array}$ & 3.76 & 0.806 \\
\hline
\end{tabular}




\begin{tabular}{|c|c|c|c|c|c|c|c|}
\hline $\begin{array}{l}\text { 我害怕说汉语时, 其他同学会嘲 } \\
\text { 笑我。 }\end{array}$ & $\begin{array}{l}4.5 \\
(10)\end{array}$ & $\begin{array}{l}22.2 \\
(49)\end{array}$ & $\begin{array}{l}34.8 \\
(77)\end{array}$ & $\begin{array}{l}29.0 \\
(64)\end{array}$ & $\begin{array}{l}9.5 \\
(21)\end{array}$ & 3.16 & 1.02 \\
\hline $\begin{array}{l}\text { 当汉语老师问到我一些没有事先 } \\
\text { 准备好的问题时, 我会感到紧张 }\end{array}$ & $1.4(3)$ & $\begin{array}{l}4.5 \\
(10)\end{array}$ & $\begin{array}{l}26.7 \\
(59)\end{array}$ & $\begin{array}{l}51.1 \\
(113)\end{array}$ & $\begin{array}{l}16.3 \\
(36)\end{array}$ & 3.76 & 0.825 \\
\hline
\end{tabular}

1=非常不同意，2=不同意，3=一般，4=同意，5=非常同意

\section{测试焦虑}

从某种程度来说, 任何形式的测试往往会给学生造成一定的焦虑感（李洪波\& 刘莉，2008）。通过表五, 测试焦虑中“我担心汉语考试不及格”（均值=4.09） 因子是众多因子中焦虑值最高的。正如周海燕（2007）在其研究中提到“学习者 往往因为担心考试成绩不理想而产生焦虑”这一论点相符合。由于学生注重汉语 考试成绩, 因此非华裔生在回答“上汉语课时, 我会想着和课程无关的事 (如发 白日梦, 不专心等) ”（均值=2.45）, 这一反向问题反应“非常同意”的人数并 不多, 更是测试焦虑因子中均值最低的。非华裔生“担心跟不上汉语课的进度” （均值=4.05），“当快被老师叫到时，感觉听到自己的心跳声”（均值=3.33）或 “知道将被老师叫到时会发抖”（均值=3.18）也充分地说明他们在汉语考试时的 焦虑感。此外, 考试所产生的焦虑也让非华裔生常常在“充分准备好汉语考试, 仍然感到焦虑”（均值=3.66），甚至会因为“太紧张以致于忘记所知道的东西” （均值=3.42）。虽然, 汉语考试让非华裔生感到压力、焦虑, 但并没有因此让 非华裔生“再上多几节汉语课，感到困惑”（均值=3.39），“很烦恼上汉语课”（ 均值=3.19）, 或“比上其他课还要紧张不安”（均值=2.89）, 反而让非华裔生在 “接近上汉语课时, 越觉得有信心并感到很轻松”（均值=3.33）。由此可见, 汉 语考试的压力、焦虑并不影响非华裔生学习汉语的动力。这一调查结果表明, 适度的焦虑有利于外语学习, 它能使学习者保持适度的紧张状态, 集中精力 ( 韩程峰，2009）。

表五

测试焦虑因子之百分比, 均值和标准差分析结果

\begin{tabular}{|c|c|c|c|c|c|c|c|}
\hline 测试焦虑因子描述 & & & 2 & 3 & 4 & $\begin{array}{l}\text { 均 } \\
\text { 值 }\end{array}$ & $\begin{array}{l}\text { 标 } \\
\text { 准 } \\
\text { 差 }\end{array}$ \\
\hline $\begin{array}{l}\text { 上汉语课时, 我知道将被老师叫 } \\
\text { 到时, 我会发抖。 }\end{array}$ & $1.8(4)$ & $\begin{array}{l}15.4 \\
(34)\end{array}$ & $\begin{array}{l}49.8 \\
(110)\end{array}$ & $\begin{array}{l}28.5 \\
(63)\end{array}$ & $\begin{array}{l}4.5 \\
(10)\end{array}$ & 3.18 & 0.812 \\
\hline $\begin{array}{l}\text { 再上多几节汉语课, 也不会使我 } \\
\text { 感到困扰。 }\end{array}$ & $3.6(8)$ & $\begin{array}{l}11.3 \\
(25)\end{array}$ & $\begin{array}{l}38.9 \\
(86)\end{array}$ & $\begin{array}{l}34.4 \\
(76)\end{array}$ & $\begin{array}{l}11.8 \\
(26)\end{array}$ & 3.39 & 0.960 \\
\hline $\begin{array}{l}\text { 上汉语课时, 我会想着和课程无 } \\
\text { 关的事 (如发白日梦, 不专心等 } \\
\text { ）。 }\end{array}$ & $\begin{array}{l}15.8 \\
(35)\end{array}$ & $\begin{array}{l}38 \\
(84)\end{array}$ & $\begin{array}{l}33.9 \\
(75)\end{array}$ & $9(20)$ & $3.2(7)$ & 2.45 & 0.969 \\
\hline $\begin{array}{l}\text { 考汉语时, 我通常感到轻松自在 } \\
\text { 。 }\end{array}$ & $\begin{array}{l}5.9 \\
(13)\end{array}$ & $\begin{array}{l}27.6 \\
(61)\end{array}$ & $\begin{array}{l}51.6 \\
(114)\end{array}$ & $\begin{array}{l}13.1 \\
(29)\end{array}$ & $1.8(4)$ & 2.77 & 0.816 \\
\hline 我担心汉语考试不及格。 & $3.6(8)$ & $4.1(9)$ & 11.3 & 41.2 & 39.8 & 4.09 & 0.997 \\
\hline
\end{tabular}




\begin{tabular}{|c|c|c|c|c|c|c|c|}
\hline & & & (25) & (91) & (88) & & \\
\hline $\begin{array}{l}\text { 我无法理解为什么有些人很烦恼 } \\
\text { 上汉语课。 }\end{array}$ & $\begin{array}{l}4.5 \\
(10)\end{array}$ & $\begin{array}{l}14.5 \\
(32)\end{array}$ & $\begin{array}{l}45.1 \\
(101)\end{array}$ & $\begin{array}{l}28.1 \\
(62)\end{array}$ & $\begin{array}{l}7.2 \\
(16)\end{array}$ & 3.19 & 0.929 \\
\hline $\begin{array}{l}\text { 上汉语课时, 我会太紧张以致于 } \\
\text { 忘记我所知道的东西。 }\end{array}$ & $0.9(2)$ & $\begin{array}{l}19.9 \\
(44)\end{array}$ & $\begin{array}{l}29 \\
(64)\end{array}$ & $\begin{array}{l}35.7 \\
(79)\end{array}$ & $\begin{array}{l}14.5 \\
(32)\end{array}$ & 3.42 & 0.995 \\
\hline $\begin{array}{l}\text { 即使我充分准备好汉语考试, , } \\
\text { 我仍感到焦虑。 }\end{array}$ & $\begin{array}{l}0.5 \\
\text { (1) }\end{array}$ & $\begin{array}{l}9.0 \\
(20)\end{array}$ & $\begin{array}{l}28.5 \\
(63)\end{array}$ & $\begin{array}{l}47.5 \\
(105)\end{array}$ & $\begin{array}{l}14.5 \\
(32)\end{array}$ & 3.66 & 0.850 \\
\hline $\begin{array}{l}\text { 当我为了汉语考试准备越久, 我 } \\
\text { 越觉得困惑不安。 }\end{array}$ & $\begin{array}{l}7.7 \\
(17) \\
\end{array}$ & $\begin{array}{l}45.2 \\
(100)\end{array}$ & $\begin{array}{l}36.2 \\
(80)\end{array}$ & $\begin{array}{l}10.4 \\
(23)\end{array}$ & $\begin{array}{l}0.5 \\
(1)\end{array}$ & 2.50 & 0.801 \\
\hline $\begin{array}{l}\text { 如果有充分的准备, 上汉语课时 } \\
\text { 我就不会感到压力。 }\end{array}$ & $\begin{array}{l}10.9 \\
(24)\end{array}$ & $\begin{array}{l}29.4 \\
(65)\end{array}$ & $\begin{array}{l}40.3 \\
(89)\end{array}$ & $\begin{array}{l}15.8 \\
(35)\end{array}$ & $\begin{array}{l}3.6 \\
(8)\end{array}$ & 2.71 & 0.978 \\
\hline 我担心跟不上汉语课的进度。 & $\begin{array}{l}0.5 \\
\text { (1) }\end{array}$ & $\begin{array}{l}5.9 \\
(13)\end{array}$ & $\begin{array}{l}13.1 \\
(29)\end{array}$ & $\begin{array}{l}48.9 \\
(108)\end{array}$ & $\begin{array}{l}31.7 \\
(70)\end{array}$ & 4.05 & 0.851 \\
\hline $\begin{array}{l}\text { 我上汉语课比上其他课还要紧张 } \\
\text { 不安。 }\end{array}$ & $\begin{array}{l}6.3 \\
(14)\end{array}$ & $\begin{array}{l}27.6 \\
(61)\end{array}$ & $\begin{array}{l}41.6 \\
(92)\end{array}$ & $\begin{array}{l}19.5 \\
(43)\end{array}$ & $\begin{array}{l}5.0 \\
(11)\end{array}$ & 2.89 & 0.956 \\
\hline 我常常不想上汉语课。 & $\begin{array}{l}6.8 \\
(15)\end{array}$ & $\begin{array}{l}23.5 \\
(52)\end{array}$ & $\begin{array}{l}29.9 \\
(66)\end{array}$ & $\begin{array}{l}28.1 \\
(62)\end{array}$ & $\begin{array}{l}11.8 \\
(26)\end{array}$ & 3.14 & 1.11 \\
\hline $\begin{array}{l}\text { 当我快被老师叫到时, 我觉得我 } \\
\text { 听到自己的心跳声。 }\end{array}$ & $\begin{array}{l}1.4 \\
\text { (3) }\end{array}$ & $\begin{array}{l}12.2 \\
(27)\end{array}$ & $\begin{array}{l}45.2 \\
(100)\end{array}$ & $\begin{array}{l}34.4 \\
(76)\end{array}$ & $\begin{array}{l}6.8 \\
(15)\end{array}$ & 3.33 & 0.828 \\
\hline $\begin{array}{l}\text { 当我接近上汉语课时, 我越觉得 } \\
\text { 有信心并感到很轻松。 }\end{array}$ & $\begin{array}{l}0.9 \\
\text { (2) }\end{array}$ & $\begin{array}{c}10 \\
\text { (22) }\end{array}$ & $\begin{array}{r}51.6 \\
\text { (114) }\end{array}$ & $\begin{array}{l}29.4 \\
(65) \\
\end{array}$ & $\begin{array}{l}8.1 \\
\text { (18) } \\
\end{array}$ & 3.33 & 0.802 \\
\hline
\end{tabular}

1=非常不同意，2=不同意，3=一般，4=同意，5=非常同意

\section{结语}

焦虑对于语言学习的重要性在“外语焦虑”（foreign language anxiety）这一概念 中表现得最为清楚（刘松浩, 2010）。本研究通过对玛拉工艺大学210名修汉 语作为外语学习的非华裔生的问卷调查, 探索非华裔生的汉语学习焦虑程度和 因素。研究显示, 玛拉工艺大学的非华裔生在学习汉语时存在着焦虑, 而导致 非华裔生汉语学习焦虑的主要因素是交际焦虑。因此, 对外汉语教学者可在教 学过程中针对交际焦虑这一焦虑因素, 创造一个轻松的汉语学习环境, 以降低 非华裔生的汉语学习焦虑，提高非华裔生的汉语学习兴趣。

通过对非华裔生汉语学习焦虑的调查, 能使对外汉语研究者了解非华裔 生在汉语学习过程中产生的焦虑情况及焦虑原因, 有利于对外汉语教师帮助非 华裔生或非华裔生自己减轻汉语学习焦虑。当然, 本文尚存一些不足, 探讨之 问题不够深入, 如: 性别、专业、学习汉语阶段等变量与汉语学习焦虑的相关 性问题以及焦虑应对策略。有鉴于此，笔者将继续收集样本，以期完善非华裔 生汉语学习焦虑焦虑研究。

\section{参考文献}

韩程峰. (2009). 外语学习焦虑调适和自我效能感的培养. 基础英语教育，11(4), 49-53. 
郝秋兰. (2014). 土库曼斯坦预科留学生汉语学习焦虑研究 (硕士论文). 华中师范大学, 武汉, 中国.

何珊. (2014). 外国留学生汉语学习焦虑研究. 云南师范大学学报（对外汉语教学及研究版），12(2), 61-69.

李洪波., \& 刘莉. (2008). 浅谈外语学习中的语言焦虑问题. 辽宁师专学报（社会科学版），4, 102-105.

李宁。(2013). 留学生汉语学习焦虑问题研究 (硕士论文)。广西大学，广西， 中国.

李贤伟., \& 王金鍂. (2003). 语言焦虑对外语学习的影响. 黑龙江高教研究, 6, 155156.

李小花. (2012). 藏族学生外语课堂焦虑调查研究. 青海师范大学学报（哲学社会科学版），34(3)，146-149.

刘松浩. (2010). 第二语言习得导论- - 对外汉语教学视角. 北京: 世界图书出版公司.

彭虹. (2012). 泰国初中生汉语学习焦虑状况以及成因研究 (硕士论文). 广西大学, 广西, 中国.

钱旭菁. (1999). 外国留学生学习汉语时的焦虑. 语言教学与研究, 2, 144-154.

史利红.

(2014).

大学生网络英语学习自我效能感与外语学习焦虑和归因的关系研究.

北京印刷学院学报, 5, 54-59.

唐美玲. (2006). 外语学习焦虑研究及其对外语教学的启示. 美中教育评论，3(6), 44-48.

王银泉., \& 万玉书. (2001). 外语学习焦虑及其对外语学习的影响- 国外相关研究概述. 外语教学与研究 (外国语文双月刊)，33(2)，122-126.

徐劦., \& 李敬梅. (2015). 高校单招生外语学习焦虑之调查研究. 南京晓庄学院学报, 3, 107-110.

杨利娟. (2010). 泰国留学生汉语学习焦虑研究 (硕士论文). 西南大学, 重庆, 中国.

杨文漟., \& 章明明. (2003). 语言焦虑与教师的调控. 广州: 广州大学学报 (社会科学版)，2(5)，29-31.

张莉. (2006). 课堂内外语学习焦虑的决定因素的实证研究. US-China Foreign Language, 4(2), 57-61.

周凤敏. (2013). 初中生英语学习焦虑对学习成绩的影响. 基础英语教育, 15(5), 37.

周海燕. (2007). 外语学习中的焦虑情感因素. 孝感学院学报, 27(4), 99-101.

赵维伦., \& 刘丰. (2011). 学前儿童外语学习焦虑探析. 教育与教学研究, 25(8), 125-128.

Aida, Y. (1994). Examination of Horwitz, Horwitz and Cope's construct of foreign language anxiety: The case of students of Japanese. The Modern Language Journal, 78(2), 155-168.

Horwitz, E. K., Horwitz, M. B., \& Cope, J. A. (1986). Foreign language classroom anxiety. The Modern Language Journal, 70(2), 125-132.

Matsuda, S., \& Gobel, P. (2001). Quiet apprehension: Reading and classroom anxieties. JALT Journal, 23, 227-274. 